\title{
Development of a Perception Scale on the Use of Webquests
}

\section{Cumali ÖKSÜZ* ${ }^{*}$ Sanem UÇA**}

\begin{abstract}
In this study, it was aimed to develop a scale for identifying the users' perceptions towards the use of WebQuests. In this sense, this article describes the development and the reliability and validity study of "The Perception Scale on the Use of WebQuests". Possible explanations of the findings are discussed and interpretation of the results is provided. The scale included 41 Fivepoint Likert-type items. Data were collected from 200 pre-service teachers attending in a public university in the west coast of Turkey and 30 elementary school teachers working in the same part of Turkey in 2009. Item analysis, factor analysis and the reliability analysis were conducted in the process of the development of the scale. The results of the study indicate that the scale has good psychometric properties and can be used reliably to have WebQuest users' perceptions on the use of WebQuest.
\end{abstract}

Key Words: WebQuest, WebQuest Scale, Reliability and Validity

\footnotetext{
* Assist. Prof. Dr. Adnan Menderes University Tel: 025621410 61-1576 E-mail: cumalioksuz@gmail.com

** Adnan Menderes University Tel: 025621410 61-1576 E-mail: sanemuca@gmail.com
} 


\section{SUMMARY}

Purpose and significance: WebQuest is a learning activity and a method utilized by educators to engage students in an inquiry based learning environment. Educators use WebQuests as a way to make good use of the internet while engaging their students in critical thinking, knowledge application, social skills and scaffolded learning. During this activity learners read, analyze, and synthesize information using the WWW. Webquests were invented by Bernie Dodge and Tom March in 1995. Since then more attention has been paid to this method and the method has spread around the world. Although the use of WebQuests has spread, we have found no scale to obtain information from users towards using WebQuests. Thus, it was aimed at developing a scale for identifying the users' perception on the use of WebQuests. In this article, the development process of the scale is explained, possible explanations of the findings are discussed and interpretation of the results are provided.

Methods: To obtain users' perception on the use of WebQuests, the reliability and validity study of "The Perception scale on the use of WebQuest" was conducted. Scale data required for the development of the scale was gathered from two groups. Participants were 200 pre-service teachers attending in a public university in the west coast of Turkey and 30 elementary school teachers working in the same part of Turkey in 2009. In the development process, related literature is examined, item pool including 54 items is developed, teachers and Experts' (in Curriculum and Instruction, Instructional Technology, Assessment and Evaluation and Turkish Language fields) opinions and comments were taken for content validity. In final, a 41 Five-point Likert-type item consisting of positively and negatively worded items included in the scale. Participants were required to use at least two WebQuests prepared by researchers and and then filled out the scale. Item analysis, factor analysis and the reliability analysis were conducted in the process of the development of the scale.

Results: The 41 items of Perception Scale on the Use of WebQuest (PSUW) were subjected to principal component analysis (PCA) using SPSS. Prior to performing PCA the suitability of data for factor analysis was assessed. Inspection of the correlation matrix revealed the presence of many coefficients of .3 and above. The Kaiser-Meyer-Oklin value was .90 , exceeding the recommended value of .6 (Kaiser 1974) and the Barlett's Test of Sphericity (Bartlett, 1954) reached statistical significance $(\chi 2=4100,94$; $\mathrm{p}=.00$ ), supporting the factorability of the correlation matrix. 
Principal component analysis revealed a structure with items clustered into four factors named as general features, benefits for students, benefits for teachers and teaching-learning process. To aid in the interpretation of these four components, varimax rotation was performed. The rotated solution revealed the simple structure with four of the components showing a number of strong loadings, and all variables loading substantially on only one component. The four factor solution explained 50.7 per cent of the variance, with component 1 contributing 19.4 per cent, component 2 contributing 11.2 per cent, component 3 contributing 10.3 per cent and component 4 contributing 10.1 per cent.

Moreover, total item scores were calculated, and regression analysis to find the correlation between each scale item and total scale score was carried out. According to the results, there has been a lineer and positive relation between each of 41 items and total score. "p" value was also found statistically significant $(\mathrm{p}<0.001)$. To compare the mean scores and define difference based on the total item means between high-low-27-percent group, independent t-test was calculated and result was found significant $(\mathrm{p}<0.001)$. This result interpreted as a sign of scale's criterion-related validity.

Discussion and Conclusions: The results of the study indicate that the scale has good psychometric properties and can be used reliably to obtain perceptions from WebQuest users on the use of WebQuests. It is expected that this newly developed perception scale will contribute to future studies on WebQuests. 


\section{"Webquest" Kullanımına İlişkin Algı Ölçeğinin Geliştirilmesi}

\section{Cumali ÖKSÜZ ${ }^{*}$ Sanem UÇA **}

ÖZ. Bu araştırmada WebQuest kullanımına ilişkin kullanıcıların algılarını belirlemek amacıyla bir ölçek geliştirilmesi amaçlanmıştır. Bu anlamda "WebQuest Kullanımına İlişkin Algı Ölçeği” ismi ile geliştirilen bu ölçeğe ilişkin yapılan geçerlik, güvenirlik çalışmaları, elde edilen bulgular ve yapılan yorumlar bu makalenin içeriğini oluşturmaktadır. Geliştirilen ölçek 41 maddeden oluşan beşli Likert tipi bir yapıda hazırlanmıştır. Ölçek formu 2009 yılında Türkiye'nin batı kıyısında yer almakta olan bir kamu üniversitesinde 3. ve 4 . sınıfta eğitim görmekte olan 200 öğretmen adayına ve belirtilen bölgede sınıf öğretmeni olarak çalışmakta olan 30 öğretmene uygulanmıştır. Ölçeğin geliştirilmesinde uygulanan analizler; faktör analizi, güvenirlik analizi ve madde analizidir. Araştırma sonuçlarına bakılarak geliştirilen ölçeğin psikometrik özelliklerinin güçlü olduğu ve WebQuest kullanıcılarının bu tekniğin kullanımına yönelik algılarını belirlemek amacıyla güvenilir bir şekilde kullanılabileceği belirtilmiştir.

Anahtar Sözcükler: WebQuest, WebQuest Ölçeği, Geçerlik ve Güvenirlik

* Yrd. Doç. Dr. Adnan Menderes Üniversitesi Tel: 025621410 61-1576 E-posta:

cumalioksuz@gmail.com

**Adnan Menderes Üniversitesi Tel: 025621410 61-1576 E-posta: sanemuca@gmail.com 


\section{GíRiş}

WebQuest, Dodge (1995) tarafından geliştirilmiş olup, eğitim ile genel ă̆ (World Wide Web) kaynaklarının birlikte çalışılması sonucunda ortaya çıkarılmıştır. WebQuest, internet tabanlı bir öğretim tekniği ve üst düzey düşünme becerilerini geliştiren bir etkinlik aracı olarak tanımlanabilir. Yapılandırılmış bir ortam olarak WebQuest, internet ortamının karmaş1k yapısı içerisinde ortaya çıkan sorunlara getirilebilecek çözüm yollarından birisidir. $\mathrm{Bu}$ anlamda son zamanlarda eğitimciler arasında sıklıkla kullanılmaya başlanmıştır.

Bernie Dodge, WebQuest hakkında öğretmenlerin bilgi edinmelerini sağlamış ve geliştirdiği WebQuest etkinlikleriyle öğretmen ve öğretmen adaylarına model olmuş ve bu konuda örnekler sunmuştur. WebQuest konusunda çalışmalar yapan önemli bir diğer araştırmacı ise Tom March'tır. Tom March Dodge'ın çalışmalarını zenginleştirmiş, örnek WebQuest etkinliklerini çeșitlendirmiş ve bu tekniğin öğretimde kullanılması üzerine makaleler yazarak öğretmenler ve öğretmen adaylarını bilgilendirmiştir. March (1998), WebQuest'i yapılandırılmış öğrenme ortamı (scaffolded learning structure) olarak tanımlamış ve bu yapının öğrenciyi aktif kılan mekanizmasına vurgu yapmıştır.

Dodge'nin WebQuest öğretim tekniği kısa zamanda eğitimciler arasında kabul görmüş; diğer araştırmacılar, öğretmenler, öğretmen adayları ve öğretim elemanları tarafından sıklıkla kullanılan internet tabanlı bir kaynak haline gelmiştir. Bu amaçla Dodge ve March tarafından San Diego Eyalet Üniversitesi, Freed-Hardeman Üniversitesi ve kendi özel isimleri ile açtıkları internet sitelerinde çeşitli WebQuestler yer almaktadır. Hong Kong Üniversitesi'nde olduğu gibi farklı üniversite ve kurumlarda da WebQuest kaynaklarına rastlamak mümkündür.

WebQuest'in 4 alt yapısı bulunmaktadır. $\mathrm{Bu}$ alt yapılar eleştirel düşünme, bilgi kazanımı, sosyal beceriler ve yapılandırılmış öğrenme (scaffolded learning) (Brucklacher ve Gimbert, 1999; Dodge, 1995, 2001; Pohan ve diğerleri, 1998; Vidoni ve diğerleri, 2002) olarak belirtilmektedir. Zheng, Stucky, McAlck, Menchana ve Stoddart (2005) WebQuest'in öğrenenler tarafından öğretimsel bir araç olarak görülmediği kanısından yola çıkarak WebQuest'in yukarıda bahsedilen 4 alt yapısına vurgu yapmış ve bu alt yapıların oluşturulması ile ilgili olarak benzer bir çalışma gerçekleştirmişlerdir. Yaptıkları analiz sonucunda 3 faktörle karşılaşmışlardır. Araştırmacıların ortaya koyduğu ve WebQuest öğrenenlerin kritik faktörler olarak belirledikleri bu faktörler; yapılandırmacı problem çözme, sosyal etkileşim ve yapılandırılmış ögretim faktörleri olarak 
ifade edilmiştir. Araştırmacılar, öğretim amaçlı WebQuest tasarlayanların bu yeni yapıları göz önünde bulundurmaları gerektiğini belirtmişlerdir.

Uluslar arası platformda, farklı uzmanlık alanlarından birçok araştırmacinın WebQuest üzerine çalıştığı görülmektedir. Bu araştırmacılardan Cruz ve Carvalho (2008) öğrencilerin WebQuest yoluyla öğrenmelerini ölçmek ve WebQuest tekniğine yönelik yaklaşımlarını görmek istemişlerdir. Bu amaçla hazırlanmış olan "Tutankaman" adlı WebQueste ilişkin öğrencilerin görüşlerini almışlar, ayrıca bu yöntemle öğrencilerin bilgi edinimini ve grup çalışmalarındaki performanslarını araştırmışlardır. Araştırma sonucunda öğrencilerin WebQuesti kolaylıkla kullanabildiklerini ve WebQuest kullanımının öğrencileri öğrenmeye motive ettiğini ortaya koymuşlardır. Ayrıca, araştırmacılar WebQuest kullanımının öğrencilerde araştırma, analiz etme, projeyi özetleme, farklı kaynaklara ulaşabilme, tarih okur-yazarlığ 1 ve bir ürün oluşturma gibi kritik özellikleri ortaya çıkardığını belirtmişlerdir.

Lim ve Hernandez (2007) WebQuest'i çağdaş evlilik ve aile terapisi teorisi gibi sosyal ve evrensel meselelerde eleştirel düşüncenin gelişimi ve uygulanması amacıyla bir araç olarak kullanmışlardır. Araştırma sonuçları WebQuest'in aile terapi kurslarında kullanılmasının öğrencinin evrensel meseleler hakkında daha fazla farkındalık kazanmasını sağladığı, kendi müdahale modellerini geliştirmede yaratıcılıklarını artırdığı, öğrencinin farklı bilgi ve bakış açılarının farkına vararak, bu bilgi ve bakış açılarını tartışıp çözüme dahil etmelerini sağladığını ortaya koymuştur.

Ülkemizde de WebQuest konusu araştırmacılar arasında ilgi uyandırmış; Halat $(2008 ; 2007 ; 2005 ; 2001)$ bu konuda örnekler sunmuş ve öğretmen adayları ile araştırmalar yapmıştır. Halat'ın yaptığı araştırmalar; WebQuest ile matematik öğretiminin motivasyona etkisi (2008), Matematik öğretiminde WebQuest kullanımına ilişkin öğretmen adaylarının görüşleri (2007); WebQuest'in öğretim amaçlı kullanımı (2005) ve Geometrinin WebQuest yoluyla kavratılması (2001) çalışmalarıdır. Bu çalışmalarda Halat, WebQuest'in öğretmen adaylarının motivasyonunu artırdığı ve matematik öğretimine karşı olumlu tutum geliştirmelerine katkı sağladığını (2008); WebQuest'in matematik öğretiminde kullanımına yönelik öğretmen adaylarında yaygın bir görüş bulunduğunu (2005), öğretmen adaylarının ders kitab1 ve geleneksel öğretime karşı gerçek yaşam durumlarını da modelleyebilen bir ortam olarak WebQuest in ögretimde kullanımına daha istekli bakabildiklerini (2001) ortaya koymuştur.

Ülkemizde ayrıca Kurtuluş ve Kılıç (2009) WebQuest destekli işbirlikli öğrenme yönteminin matematik dersindeki erişiye etkisini araştırmış ve 
WebQuest destekli işbirlikli öğrenme yönteminin öğrencilerin matematik dersindeki erişi düzeylerini yükseltmede bir faktör olduğu sonucuna ulaşmıştır.

Web ortamının sağladığı yararları göz önünde bulunduran Gülbahar, Madran ve Köse (2008), WebQuest'i, "Web Macerası" olarak Türkçeye çevirmişler ve bilgisayar yazılımları ile WebQuest hazırlama, hazır WebQuest programları üzerinde değişiklikler yapabilme olanağı sunan bir program geliştirmişler ve konuyla ilgili araştırmalar yapmışlardır. Amaçları aynı zamanda etkileşimli dinamik WebQuestler geliştirmek olan yazarlar statik olarak hazırlanan WebQuestlerin amacına ulaşamayacağını ve WebQuestlerin etkileşimli olarak hazırlanması gerektiğini belirtmişlerdir. $\mathrm{Bu}$ amaçla hazır WebQuestlerin dinamik hale getirilebileceği, üzerinde değişikliklerin yapılabileceği, hazırlanan WebQuestlerin izlenebileceği, ayrıca forum yoluyla iletişimin kurulabileceği kapsamlı bir WebQuest platformu oluşturmuşlardır. $\quad \mathrm{Bu}$ platform http://www.maceraci.web.tr/index.php adresinden hizmet vermektedir. Halen geliştirilmekte olan bu platform teorik alt yapısı ve tasarımındaki dinamik yapısı sayesinde WebQuest konusunda dünyadaki en iyi platform olma yolundadır.

Bu makalede WebQuest üzerine bugüne kadar yapılmış olan bazı ulusal ve uluslararası araştırma ve çalışma sonuçlarına değinilmiş ve WebQuest'i oluşturan yapılardan söz edilmiştir. Yukarıda sözü edilen araştırmalardan da görüleceği üzere eğitimde WebQuest kullanımına ilişkin kullanıcıların algısı üzerine ilgili literatürde bir ölçeğe rastlanmamıştır. Spesifik olarak, oluşturulan WebQuestlerle ilgili olarak nitel görüş almak veya o WebQuest' in etkililiğini ölçmek yanında internet tabanlı bir öğrenme platformu olan WebQuest kullanımının öğretimde genelde ne gibi bir etki yarattığının ölçülmesi gerekmektedir. Bu anlamda WebQuest kullanımının öğrenme ve öğretme ortamına ne gibi katkılar sağladığının kullanıcılar açısından ve de özellikle eğitimciler açısından değerlendirilebildiği geçerli ve güvenilir bir ölçme aracına gereksinim duyulmaktadır. Bu amaçla bir ölçek geliştirilmesi hedeflenmiş ve bu çalışma ile Webquest kullanımına ilişkin bir alg1 ölçeği geliştirilmiştir. Yapılan geçerlik, güvenirlik çalışmaları, elde edilen bulgular ve yapılan yorumlar bu makalenin içeriğini oluşturmaktadır.

\section{YÖNTEM}

\section{Çalışma Grubu}

Araştırma çalışma grubunu; 2009 -2010 öğretim yılında Aydın Adnan Menderes Üniversitesi Eğitim Fakültesi Sinıf Öğretmenliği bölümünde öğrenim gören 200 adet 3. ve 4. sınıf öğrencisi ve Aydın il merkezi 
ilköğretim birinci kademede görev yapan 30 adet sınıf öğretmeninden oluşan toplam 230 kişi oluşturmaktadır. Ölçeğin eğitimsel değeri ve ölçek maddelerinin eğitim terimleri bakımından karşılığının kullanıcılar tarafından tam olarak değerlendirilebilmesi için ölçek geliştirmede yer alan kullanıcıların eğitimci olmaları önem taşımaktadır. $\mathrm{Bu}$ anlamda kullanıcıların algılarının edinildiği bu çalışmada kullanıcılar olarak öğretmen ve öğretmen adayları belirlenmiştir.

\section{Ölçeğin Geliştirilmesi ve Ön Deneme Uygulaması}

Ölçek geliştirme işleminde öncelikle ölçek maddeleri hazırlanmıştır. Bu süreçte araştırmacılar tarafindan öğretim teknolojisinde kullanılan araçlar, WebQuest'e ilişkin literatür incelenmiş (Dodge, 1995; March 1998; Cruz ve Carvalho, 2008; Halat 2008; 2007; 2005; 2001; Kurtuluş ve Kılıç 2009), bu kaynakların kullanımına ilişkin temel özellikler tanımlanmıştır. Özellikle WebQuest'in 4 alt yapısı olan eleştirel düşünme, bilgi kazanımı, sosyal beceriler ve yapılandırılmış öğrenme (scaffolded learning) (Brucklacher ve Gimbert, 1999; Dodge, 1995, 2001; Pohan ve diğerleri, 1998; Vidoni ve diğerleri, 2002) ve Zheng, Stucky, McAlck, Menchana ve Stoddart (2005) tarafindan ortaya konulan yapılandırmacı problem çözme, sosyal etkileşim ve yapılandırılmış öğretim faktörleri temel alınmıştır. WebQuest öğrenenlerin çok önemli boyutlar olarak belirledikleri bu faktörlere ait özellikler ve ilgili literatür taraması 1şığında ölçek maddeleri geliştirilmiş ve 54 maddeden oluşan bir ölçek oluşturulmuştur.

$\mathrm{Bu}$ ölçeğin beklenen davranışları ne derece ölçtüğünün tayin edilmesi (Balc1, 2005), yani kapsam geçerliğinin sağlanması amacıyla uzman görüşüne başvurulmuştur. $\mathrm{Bu}$ anlamda ölçek maddeleri eğitim bilimleri alanından 2 öğretim üyesinin, Bilgisayar ve Öğretim Teknolojisi alanından bir öğretim üyesinin ve ölçme ve değerlendirme alanından bir öğretim üyesinin görüşlerine sunulmuştur. Ayrıca, dil bakımından geçerliğinin anlaşılabilmesi için ölçek, Türk dili alanında uzman bir öğretim üyesinin görüşlerine sunulmuştur. Ayrıca 2 lisansüstü öğrencisine ve sinıf öğretmenliği bölümü 3 . Sinıfta eğitim gören 8 adet öğretmen adayına verilerek onların dil konusundaki görüşleri alınmıştır. $\mathrm{Bu}$ görüşler neticesinde bu maddelerden ekleme ve çıkarmalar yapılmıştır. Alınan görüş ve öneriler doğrultusunda 13 maddenin ölçekten çıkarılmasına ve 8 maddenin düzeltilmesine karar verilmiş ve 41 maddelik nihai ölçek hazırlanmıştır.

Hazırlanan "WebQuest Kullanımına İlişkin Algı ölçeği”" Likert tipi beşli dereceleme yöntemi ile belirlenmeye çalışılmıştır. Beşli dereceleme yapılan bu ölçekte derecelemeler; tamamen katılıyorum (5), katıliyorum (4), 
kararsızım (3), katılmıyorum (2) ve hiç katılmıyorum (1) şeklinde belirlenmiştir. Ölçekte 1., 4., 6., 25., 16., 26., 28., 29., 35., 37. maddeler olumsuz maddeler olup, bu maddelerin veri girişleri yapılırken tersten kodlama yapılmıştır. Bu maddeler için derecelemeler, tamamen katılıyorum (1), katılıyorum (2), kararsızım (3), katılmıyorum (4) ve hiç katılmıyorum (5) ş̧eklinde belirlenmiştir.

Ölçek Aydın ili Merkez İlköğretim Okulları birinci kademeden 30 öğretmen ve eğitim fakültesi sinıf öğretmenliği bölümünde 3 . ve 4. sinıfta eğitim görmekte olan 200 öğretmen adayına verilerek toplamda 230 kişiye uygulanmıştır. Uygulama yapılan grubun WebQuest'i önceden bilmedikleri gözlemlenmiştir. Uygulama öncesinde araştırmacılar tarafından iki adet WebQuest hazırlanmıştır. Hazırlanan WebQuestlerden birincisi ilköğretim 2. sınıf Geometri alt öğrenme alanı ile ilgili olarak hazırlanmıştır. $\mathrm{Bu}$ WebQuest'te "Geometrik Cisimler" konusu işlenmiştir. Hazırlanan diğer WebQuest ise 4. sınıf veri alt öğrenme alanı ile ilgili olarak hazırlanmış ve "Sütun Grafiği" konusu işlenmiştir. Öğretmen adayları 20 kişilik gruplar halinde bilgisayar laboratuarına alınmış ve hazırlanan bu iki WebQuest kendilerine kullandırılmıştır. Kullanımın ardından kendilerinden "WebQuest Kullanımına İlişkin Alg1 Ölçeği”ni cevaplamaları istenmiştir. Öğretmenler ile yapılan çalışmada ise "Teknolojinin Matematik Eğitimine Entegrasyonu Projesi (TME ${ }^{2}$ )" çalıştayı kapsamında kendilerine yine aynı iki WebQuest kullandırılmıştır. Kullanımlarının ardından öğretmenlerden "WebQuest Kullanımına İliş̧kin Alg1 Ölçeği”ni cevaplamaları istenmiştir.

\section{Verilerin Çözümlenmesi}

Ölçeğin geçerlilik ve güvenirlik analizleri kapsamında ölçeğin yap1 geçerliğini belirlemek amaciyla SPSS 11.5 istatistik programında faktör analizi, güvenirliğini belirlemek için Cronbach Alfa güvenirlik katsayısı, maddelerin ayırt edicilik özelliğini belirlemek için t değerleri hesaplanmıştır.

\section{BULGULAR ve YORUMLAR}

\section{Ölçeğin Faktör Analiz Çalışmaları}

Örneklem büyüklüğünün yeterli olup olmadığını belirlemek amacıyla Kaiser-Meyer-Olkin testi (KMO) yapılmıştır. Bu testin sonucunda KMO değeri 90 olarak hesaplanmıştır. Örneklem büyüklüğünün yeterliliğinin bir ölçütü olarak gösterilen KMO değeri (Akgül ve Çevik, 2003) bu çalışmadaki örneklem büyüklüğünün yeterli olduğunun bir göstergesi olarak kabul edilmiştir. İyi bir faktör analizi için minumum KMO indeks değerinin .6 olduğu belirtilmiş ve .6'dan yüksek olması önerilmiştir (Tabachnick ve Fidel, 1996; Büyüköztürk, 2007). Ayrıca faktör analizinde evrendeki 
dağılımın normal olması gerekmektedir. Çalışma sonucunda gerçekleştirilen analizde Bartlett testi anlamlı bulunmuştur $(\chi 2=4100,94 ; \mathrm{p}=.00)$. Bartlett katsayısının anlamlı çıkması evrendeki dağılımın normal olduğunun ve verilerin faktör analizi için uygunluğunun bir göstergesidir (Tavşancıl, 2002: 51). Bu anlamda bu değer dağılımın normalliğinin bir göstergesi olarak kabul edilmiştir.

Ölçeğin yapı geçerliliğini belirlemek için faktör analizi uygulanmıştır. Ölçeğin faktör yapılarını tanımlamak üzere önce temel bileşenler analizi (PCA), daha sonra ise temel bileşenlere göre Varimax dik döndürme tekniği kullanılmıştır. Faktörün tanımladığı maddeyi ölçmesi için o faktörle olan ilişkisini gösteren faktör yük değerinin 0.45 ve daha yüksek olması tercih edilir. Ancak az sayıdaki madde için yük değeri 0.30'a kadar düşürülebilir (Büyüköztürk, 2007). Bu araştırmada bir maddenin bir faktörde gösterilebilmesi için en az “.40”"lk bir faktör yüküne sahip olması ve maddelerin bulundukları faktördeki yük değerleri ile diğer faktörlerdeki yük değerleri arasındaki farkın ".10" ve daha yukarı olması şartları aranmıştır. Büyüköztürk (2007) çok faktörlü bir yapıda birden fazla yüksek yük değeri veren maddenin binişik madde olarak nitelendirmiş ve ölçekten çıkarılması gerektiğini belirtmiştir. Ölçeğin yapı geçerliliğini belirlemek için yapılan faktör analizine yukarıda belirtilen şartlara uyan 41 madde dahil edilmiştir. Faktör analizinin sonuçlarında ölçekte yer alan maddelerin tümünün yük değerlerinin .40 'un üzerinde olduğu ve faktör analizi sonuçlarına göre ölçekten herhangi bir maddenin çıkarılmasına gerek olmadığı görülmüştür. Yapılan analiz sonucunda ölçeğin öz değeri 1 den büyük varyansın \%50'sini açıklayan dört faktör elde edilmiştir. Birinci boyutta 17, ikinci boyutta 10 , üçüncü boyutta 7 ve dördüncü boyutta 7 madde yer almaktadır.

Faktör analizi sonuçlarına göre ölçeğin faktör sayısı, maddelerin faktör yükleri ve açıkladıkları ortak varyans Tablo 1'de sunulmuştur.

Tablo 1 incelendiğinde, 41 maddenin dört faktör altında toplandığ görülmektedir. Birinci faktör 17 maddeden oluşmakta, maddelerin faktör yük değerleri .733 ile .419 arasında değişmekte ve toplam varyansın \%19.34'ünü açıklamaktadır. İkinci faktörde 10 madde bulunmakta, maddelerin faktör yük değerleri .711 ile .415 arasında değişmekte ve bu faktör toplam varyansın \%11.23'ünü açıklamaktadır. Üçüncü faktörde 7 madde bulunmakta, maddelerin faktör yük değerleri .796 ile .484 arasında değişmekte ve bu faktör toplam varyansın \%10.31'ini açıklamaktadır. 
Tablo 1. WebQuest Kullanımına İlişsin Algı Ölçeği Faktör Analizi Sonuçları

\begin{tabular}{|c|c|c|c|c|c|}
\hline \multirow[t]{2}{*}{ Madde } & \multirow{2}{*}{$\begin{array}{l}\text { Ortak } \\
\text { Faktör } \\
\text { Varyansı }\end{array}$} & \multicolumn{4}{|c|}{ Dik Döndürülmüş Faktörler için Yük Değerleri } \\
\hline & & 1. Faktör & 2. Faktör & 3. Faktör & 4. Faktör \\
\hline M1 & .590 & .733 & & & \\
\hline $\mathrm{M} 20$ & .478 & .673 & & & \\
\hline M23 & .480 & .638 & & & \\
\hline M21 & .430 & .631 & & & \\
\hline M22 & .472 & .612 & & & \\
\hline M12 & .527 & .612 & & & \\
\hline M2 & .490 & .611 & & & \\
\hline M8 & .498 & .607 & & & \\
\hline M11 & .426 & .596 & & & \\
\hline M3 & .452 & .582 & & & \\
\hline M10 & .580 & .561 & & & \\
\hline M9 & .496 & .550 & & & \\
\hline M16 & .526 & .539 & & & \\
\hline M25 & .541 & .522 & & & \\
\hline M5 & .335 & .457 & & & \\
\hline M18 & .328 & .452 & & & \\
\hline M24 & .237 & .404 & & & \\
\hline M41 & .559 & & .711 & & \\
\hline M40 & .624 & & .706 & & \\
\hline M32 & .641 & & .623 & & \\
\hline M34 & .444 & & .603 & & \\
\hline M37 & .572 & & .589 & & \\
\hline M33 & .553 & & .576 & & \\
\hline M39 & .431 & & .532 & & \\
\hline M38 & .472 & & .505 & & \\
\hline M36 & .332 & & .499 & & \\
\hline M35 & .404 & & .415 & & \\
\hline M14 & .683 & & & .796 & \\
\hline M7 & .658 & & & .772 & \\
\hline M6 & .545 & & & .720 & \\
\hline M17 & .538 & & & .633 & \\
\hline M15 & .417 & & & .623 & \\
\hline M13 & .474 & & & .551 & \\
\hline M19 & .572 & & & .484 & \\
\hline M28 & .652 & & & & .660 \\
\hline M27 & .504 & & & & .636 \\
\hline M29 & .601 & & & & .596 \\
\hline M4 & .418 & & & & .526 \\
\hline M31 & .538 & & & & .495 \\
\hline M26 & .310 & & & & .466 \\
\hline M30 & .337 & & & & .433 \\
\hline
\end{tabular}


Dördüncü faktörde 7 madde bulunmakta, maddelerin faktör yük değerleri .660-.433 arasında değişmekte ve bu faktör toplam varyansın \%10.11'ini açıklamaktadır. Dört faktörün açıkladıkları varyans miktarı \%50.707'dir. Faktörlerin her bir maddeye ilişkin açıkladıkları ortak varyans miktarı ise, .683 ile .237 arasında değişmektedir.

Ön deneme uygulamasında elde edilen faktörler "Genel Özellikler, Öğrenciye Kazandırdıkları, Öğretmene Kazandırdıkları ve ÖğrenmeÖğretme Sürecine Etkisi” şekilde adlandırılmıştır. Bu adlandırmanın altında yer alan bazı maddeler aşağıda sunulmuş̧ur.

\section{Faktör 1: Genel Özellikler}

$\mathrm{Bu}$ faktör bir öğretim tekniği olarak WebQuest kullanımının hangi kapsama sahip olacağ 1 , ne gibi temel özelliklerinin bulunduğu, ne tür avantajları ve dezavantajları bulunduğu anlamında bir fikir veren ve kapsayıcı olarak yer alan bir faktördür. Öğretime entegre edilecek bir araç olarak ele alınabilecek WebQuest' in felsefesi, yol açtığı yenilikler ve problem çözümündeki rolüne ilişkin kullanıcı algısı bu boyut altında elde edilebilir.

$\mathrm{Bu}$ faktör altında yer alan bazı maddeler şu şekilde sıralanabilir; WebQuest tüm konu alanlarının (Fen, Matematik, Türkçe vb.) öğretiminde kullanılamaz, WebQuest ile öğretim yapılandırmacı yaklaşımı desteklemektedir, WebQuest öğretimde birçok teknolojinin kullanılmasına olanak sağlar, WebQuest tekniğinde öğretmen iyi bir rehber konumundadır, WebQuest süreci değerlendiren bir öğretim tekniği değildir, WebQuest gerçek yaşam problemleri ile ilişkilidir, WebQuest karmaşık gözüken problemlerin çözülmesine olanak sağlar.

\section{Faktör 2: Öğrenciye Kazandırdıkları}

WebQuest' in bir öğretim tekniği olarak kullanılması durumunda öğrenciye kazandırılabilecek özelliklerin sıralandığg bir faktördür. Öğrencinin aktif ve merkezde olup olmadığından yola çıkılarak mantık ve muhakeme, eleştirel düşünme becerisi, yaratıcılık gibi diğer bazı kritik eğitimsel yeterliklerin kazandırılıp kazandırılamayacağına ilişkin kullanıcı algisı bu boyut altında elde edilebilir. Bu faktör altında yer alan bazı maddeler şu şekilde sıralanabilir; WebQuest öğrencinin araştırma becerilerini geliştirir, WebQuest, öğrencinin mantık ve muhakeme yapma yeteneğini geliştirir, WebQuest öğrencinin araştırma becerilerini geliştirir, WebQuest öğrencinin yaratıcılığını geliştirir, WebQuest öğrencinin eleştirel düşünme becerisini geliştirir. 


\section{Faktör 3: Öğretmene Kazandırdıkları}

WebQuest' in öğretim sürecinde kullanılması durumunda öğretmene hangi açlardan yardımcı olabileceği ile ilgili fikirlerin ve öğretmene kazandırılabilecek faydaların sıralandığ 1 bir faktördür. $\mathrm{Bu}$ anlamda WebQuest kullanımın öğrencilerin öğrenmesi, başarısı, tutumu, eleştirel düşünmesi vb. konularda öğretmene bilgi verip veremeyeceğine ilişkin kullanıc1 algisı bu boyut altında elde edilebilir. Bu faktör altında yer alan bazı maddeler şu şekilde sıralanabilir; WebQuest öğrencinin eleştirel düşünme becerisi hakkında öğretmene fikir verir, WebQuest öğrencinin teknoloji yeterlilikleri hakkında öğretmene bilgi verir, WebQuest öğrencinin konu ile ilgili başarıları hakkında öğretmene bilgi verir, WebQuest öğrencinin konuya ilişkin tutumu hakkında öğretmene fikir verir, WebQuest öğrencinin grup içi çalışma becerisi hakkında öğretmene bilgi verir.

\section{Faktör 4: Öğrenme ve Öğretme Sürecine Etkisi}

WebQuest' in bir öğretim tekniği olarak kullanılması durumunda öğrenme ve öğretme sürecine katabileceği özelliklerin sıralandığı bir faktördür. Öğrencilerin bireysel, grup, işbirlikli çalışma ve iletişim becerileri ile ilgili olarak WebQuest'in öğrenme ve öğretme sürecine kattığı değerlere ilişkin kullanıcı algısı bu faktör altında elde edilebilir. Bu faktör altında yer alan bazı maddeler şu şekilde sıralanabilir; WebQuest bireysel öğrenmeyi desteklemez, WebQuest grup yoluyla öğrenmeyi desteklemez, WebQuest çoklu zekaya dayalı öğrenmeyi destekler, WebQuest öğretmen - öğrenci arasındaki iletişimi geliştirir.

\section{Ölçeğin Güvenirlik Çalışması}

WKAÖ ölçek maddeleri arasındaki iç tutarlılık Cronbach Alpha (Alfa) Güvenirlik Katsayısı ile hesaplanmıştır. Her bir faktör için hesaplanan güvenirlik katsayıları sırasıyla; birinci faktör için .91, ikinci faktör için .86, üçüncü faktör için .82 , dördüncü faktör için .81 olarak bulunmuştur. Özdamar (2004)'a göre ölçeğin güvenirlik katsayısının $0.80 \leq \alpha<1.00$ aralığında olması ölçeğin yüksek derecede güvenilir olduğunu göstermektedir. Bu anlamda ölçeğin güvenirliğinin bir ölçütü olarak bulunan Alpha değeri aracın güvenirliği için yeterli görülmüştür.

"WebQuest Kullanımına İlişkin Algı Ölçeği” kapsamında yer alan maddelerin her bir faktör için hesaplanan Alpha değerleri Tablo 2'de verilmiştir. 
Tablo 2. WebQuest Kullanımına İlişkin Algı Ölçeğinin Alt Faktörlerinin Isimleri ve Güvenirlik Katsayıları

\begin{tabular}{lllllll}
\hline $\begin{array}{l}\text { Faktörlerin } \\
\text { İsimleri }\end{array}$ & $\overline{\mathrm{X}}$ & $\mathbf{S S}$ & $\begin{array}{l}\text { En } \\
\text { küçük } \\
\text { değer }\end{array}$ & $\begin{array}{l}\text { En } \\
\text { büyük } \\
\text { değer }\end{array}$ & $\begin{array}{l}\text { Madde } \\
\text { sayısı }\end{array}$ & $\begin{array}{l}\text { Güvenirliği } \\
\text { (Cronbach } \\
\text { katsayısı) }\end{array}$ \\
\hline Genel Özellikler & 69.5 & 8,34 & 33 & 85 & 17 & .91 \\
\hline $\begin{array}{l}\text { Öğrenciye } \\
\text { Kazandırdıkları }\end{array}$ & 40 & 5.38 & 15 & 50 & 10 & .86 \\
\hline $\begin{array}{l}\text { Öğretmene } \\
\text { Kazandırdıkları }\end{array}$ & 26.3 & 4.21 & 9 & 35 & 7 & .82 \\
\hline $\begin{array}{l}\text { Öğrenme ve } \\
\begin{array}{l}\text { Öğretme Sürecine } \\
\text { Etkisi }\end{array}\end{array}$ & 28 & 3.96 & 10 & 35 & 7 & .81 \\
\hline Toplam & $\mathbf{1 6 5}$ & $\mathbf{1 8 . 2 7}$ & $\mathbf{7 5}$ & $\mathbf{2 0 5}$ & $\mathbf{4 1}$ & $\mathbf{. 3 3}$ \\
\hline
\end{tabular}

Uygulaması yapılan ölçme aracında alınan toplam puanlara bakıldığında ölçeğin geneline ilişkin aritmetik ortalamanın $165(\mathrm{Ss}=18.27$, Katılıyorum) olduğu görülmüştür. Her bir boyutta alınan en yüksek ve en düşük değerlere bakıldığında "Genel Özellikler" boyutunda en düşük 33 (Katılmıyorum), en yüksek 85 (Tamamen Katılıyorum) olarak; "Öğrenciye Kazandırdıkları" boyutunda en düşük 15 (Katılmıyorum), en yüksek 50 (Tamamen Katılıyorum) olarak; "Öğretmene Kazandırdıkları" boyutunda en düşük 9 (Hiç Katılmıyorum), en yüksek 35 (Tamamen Katılıyorum) olarak; "Öğrenme-Öğretme Sürecine Etkisi" boyutunda en düşük 10 (Hiç Katılmıyorum), en yüksek 35 (Tamamen Katılıyorum) olarak gözlenmiştir. En yüksek aritmetik ortalama ( $\mathrm{X}=4.1, \mathrm{Ss}=8,34$, Kat1liyorum) "Genel Özellikler" boyutunda; en düşük aritmetik ortalama ise $(X=3.76, \mathrm{Ss}=4.21$, Katılıyorum) "Öğretmene Kazandırdıkları" boyutunda görülmüsstür.

\section{Madde Analizi Çalıșması}

Ölçeğin ölçülmek istenen davranış ve tutumları ölçme gücünü belirleyebilmek üzere, madde analizi yapılmıştır. Madde analizi çalışması kapsamında çalışmada öncelikle toplam puanlar hesaplanmış ve ölçekte yer alan her bir madde için hesaplanan korelasyon değerlerinin anlamlı olup olmadığını belirlemek için regresyon katsayıları ve $t$ değerleri hesaplanmıştır. Regresyon analizi sonuçları Tablo 3'te verilmiştir. Regresyon analizi sonuçları doğrultusunda maddeler incelendiğinde, ölçekte yer alan maddeler ile toplam puan arasında doğrusal ve pozitif bir ilişki olduğu, maddelerin $\mathrm{p}$ değerleri incelendiğinde bu ilişkinin istatistiksel olarak anlamlı olduğu $(\mathrm{p}<0.01)$ görülmektedir. 
Tablo 3. Webquest Kullanımına İlişkin Algl Ölçeğinin Basit Doğrusal Regresyon ile Madde Analizi Sonuçları

\begin{tabular}{|c|c|c|c|}
\hline Madde & $\mathrm{R}$ & $\mathrm{R}^{2}$ & $\mathrm{p}$ \\
\hline M1 & .612 & .375 & .000 \\
\hline M2 & .610 & .372 & .000 \\
\hline M3 & .573 & .329 & .000 \\
\hline M4 & .496 & .246 & .000 \\
\hline M5 & .353 & .125 & .000 \\
\hline M6 & .447 & .119 & .000 \\
\hline M7 & .542 & .294 & .000 \\
\hline M8 & .631 & .398 & .000 \\
\hline M9 & .585 & .343 & .000 \\
\hline M10 & .698 & .488 & .000 \\
\hline M11 & .545 & .297 & .000 \\
\hline M12 & .638 & .407 & .000 \\
\hline M13 & .602 & .362 & .000 \\
\hline M14 & .453 & .205 & .000 \\
\hline M15 & .385 & .148 & .000 \\
\hline M16 & .636 & .404 & .000 \\
\hline M17 & .693 & .481 & .000 \\
\hline M18 & .538 & .290 & .000 \\
\hline M19 & .696 & .485 & .000 \\
\hline M20 & .506 & .256 & .000 \\
\hline M21 & .490 & .240 & .000 \\
\hline M22 & .584 & .341 & .000 \\
\hline M23 & .599 & .359 & .000 \\
\hline M24 & .442 & .196 & .000 \\
\hline M25 & .713 & .508 & .000 \\
\hline M26 & .391 & .153 & .000 \\
\hline M27 & .544 & .296 & .000 \\
\hline M28 & .673 & .453 & .000 \\
\hline M29 & .690 & .476 & .000 \\
\hline M30 & .538 & .290 & .000 \\
\hline M31 & .620 & .384 & .000 \\
\hline M32 & .616 & .380 & .000 \\
\hline M33 & .601 & .361 & .000 \\
\hline M34 & .526 & .277 & .000 \\
\hline M35 & .547 & .299 & .000 \\
\hline M36 & .458 & .210 & .000 \\
\hline M37 & .620 & .384 & .000 \\
\hline M38 & .482 & .233 & .000 \\
\hline M39 & .588 & .346 & .000 \\
\hline M40 & .598 & .358 & .000 \\
\hline M41 & .528 & .278 & .000 \\
\hline
\end{tabular}

Test maddelerinden alınan puan ile testin toplam puanı arasındaki ilişkiyi açıklamak için ölçekte maddelerin madde-toplam korelasyonları 
(Büyüköztürk, 2007) hesaplanmış ve bu hesaplamaya ilişkin korelasyonlar Tablo 4'te verilmiştir. Literatürde madde-toplam korelasyonu .30 ve daha yüksek olan maddelerin bireyleri iyi derecede ayırt ettiği, .20'den daha düşük maddelerin ise teste alınmaması gerektiği belirtilmektedir (Büyüköztürk, 2007). Buna göre tablo incelendiğinde, tüm maddelerin madde-toplam korelasyonlarının .30 ve üzerinde olduğu görülmektedir.

Tablo 4. WebQuest Kullanımına İlişkin Algı Ölçeğinin Madde Toplam Korelasyonlart ve Üst \% 27, Alt \% 27 lik Grubun Puanları Arasındaki İlişkisiz ttesti Sonuçları

\begin{tabular}{|c|c|c|c|c|c|}
\hline $\begin{array}{l}\text { Madde } \\
\text { No }\end{array}$ & $\begin{array}{l}\text { Madde -toplam } \\
\text { Korelasyonu }\end{array}$ & $\begin{array}{l}\text { Maddeler için t } \\
\text { (ய̈st \%27-Alt } \\
\text { \%27) }\end{array}$ & $\begin{array}{l}\text { Madde } \\
\text { No }\end{array}$ & $\begin{array}{l}\text { Madde-toplam } \\
\text { Korelasyonu }\end{array}$ & $\begin{array}{l}\text { Maddeler için } \\
\text { t (Üst \%27-Alt } \\
\% 27 \text { ) }\end{array}$ \\
\hline 1 & .590 & $6.316^{*}$ & 22 & .551 & $8.637 *$ \\
\hline 2 & .595 & $5.758^{*}$ & 23 & .573 & $7.62 .8^{*}$ \\
\hline 3 & .551 & $5.853^{*}$ & 24 & .398 & $5.408^{*}$ \\
\hline 4 & .475 & $5.137^{*}$ & 25 & .687 & $10.598^{*}$ \\
\hline 5 & .317 & $2.992 *$ & 26 & .367 & $5.054^{*}$ \\
\hline 6 & .409 & $5.741^{*}$ & 27 & .514 & $7.566^{*}$ \\
\hline 7 & .314 & $6.905^{*}$ & 28 & .649 & $9.100^{*}$ \\
\hline 8 & .595 & $8.363^{*}$ & 29 & .664 & $8.048^{*}$ \\
\hline 9 & .563 & $6.698^{*}$ & 30 & .506 & $6.709^{*}$ \\
\hline 10 & .693 & $8.468^{*}$ & 31 & .607 & $6.675^{*}$ \\
\hline 11 & .514 & $6.564^{*}$ & 32 & .592 & $7.176^{*}$ \\
\hline 12 & .607 & $6.771^{*}$ & 33 & .568 & $7.385^{*}$ \\
\hline 13 & .561 & $8.219^{*}$ & 34 & .498 & $6.496^{*}$ \\
\hline 14 & .401 & $6.465^{*}$ & 35 & .526 & $6.297^{*}$ \\
\hline 15 & .339 & $5.573^{*}$ & 36 & .419 & $6.620^{*}$ \\
\hline 16 & .603 & $8.038^{*}$ & 37 & .596 & $7.353^{*}$ \\
\hline 17 & .608 & $7.784 *$ & 38 & .447 & $5.654^{*}$ \\
\hline 18 & .515 & $6.131^{*}$ & 39 & .551 & $7.140^{*}$ \\
\hline 19 & .671 & $10.065^{*}$ & 40 & .585 & $7.637^{*}$ \\
\hline 20 & .480 & $5.940 *$ & 41 & .506 & $6.063^{*}$ \\
\hline 21 & .472 & $5.053^{*}$ & & & \\
\hline
\end{tabular}

Maddelerin ayırt edicilik gücünü saptamak için ise ölçekten elde edilen ham puanlar büyükten küçüğe doğru sıralandıktan sonra alt $\% 27$ ve üst \%27'yi oluşturan grupların puan ortalamalarının " $\mathrm{t}$ " değerleri hesaplanmıştır. Ölçekten aldıkları toplam puan açısından 230 katılımcının en 
yüksek puan alan üst \%27'si $(n=62)$ ile en düşük puan alan alt \%27'si $(\mathrm{n}=62)$ her bir madde ve toplam puan açısından ilişkisiz $t$ testi ile karşılaştırılmıştır. Gruplar arasında istendik yönde gözlenen farkların anlamlı çıkması, testin iç tutarlığının bir göstergesi olarak değerlendirilmiştir (Büyüköztürk, 2007). Ölçekte yer alan maddelerin faktör puanlarına göre üst $\% 27$ ile alt \%27'lik puan aralığındakilerin madde puan ortalamaları arasındaki farkın anlamlığına ilişkin t-testi sonuçları Tablo 4 'te verilmiştir.

Tablo 4'te görüldüğü üzere yapılan karşılaştırma sonucunda grupların ölçekte yer alan 41 maddenin her birinde ve toplam puanda birbirinden anlamlı derecede farklılık gösterdiği saptanmıştır. Bulunan sonuçlara göre tüm maddelerin üst \%27'lik grubun madde ortalama puanının, alt \%27'lik grubun aynı puanından anlamlı bir şekilde $(\mathrm{p}<0.001)$ yüksek olduğu görülmektedir. $\mathrm{Bu}$ durum her bir faktöre ait uç grupların her bir faktör ve toplam puan için yeter düzeyde ayırt edici özelliğe sahip olduğunu göstermektedir. Bu durumda ölçekteki maddelerin güvenirliklerinin yüksek ve aynı davranışı ölçmeye yönelik oldukları söylenebilir.

\section{SONUÇ ve ÖNERILER}

$\mathrm{Bu}$ araştırmada kullanıcıların WebQuest kullanımına yönelik algılarını belirlemek amaciyla "WebQuest Kullanımına İlişkin Alg1 Ölçeği" geliştirilmiş ve bu ölçeğin geçerlik ve güvenirlik çalışmaları yapılmıştır. Araştırmacılar tarafından geliştirilmiş olan bu ölçek olup 41 maddeden oluşmuş ve beşli Likert tipi bir yapıda hazırlanmıştır. Bu ölçek öğretmen adayları ve öğretmenlerden oluşan 230 kişilik bir gruba uygulanmış ve verilerin geçerlik ve güvenirlik hesaplamaları yapılmıştır.

Ölçeğin yapı geçerliğini belirlemek için faktör analizi ve Varimax dik döndürme uygulaması yapılmış ve yapılan faktör analizi sonuçlarına göre tüm maddelerin faktör yüklerinin .40 ve üzerinde olduğu görülmüştür. $\mathrm{Bu}$ doğrultuda ölçekten madde çıkarılmamış ve faktör analizi sonucunda ölçeğin dört alt boyuttan oluşan bir yapıya sahip olduğu belirlenmiştir. Bu boyutlar "Genel Özellikler, Öğrenciye Kazandırdıkları, Öğretmene Kazandırdıkları ve Öğrenme-Öğretme Sürecine Etkisi” olarak isimlendirilmiştir.

Ölçeğin iç tutarlılık için güvenirliği Cronbach Alpha güvenirlik katsayısı hesaplanarak incelenmiş ve her bir faktör için hesaplanan güvenirlik katsayıları sırasıyla; birinci faktör için .91, ikinci faktör için .86, üçüncü faktör için .82 , dördüncü faktör için .81 olarak bulunmuştur. $\mathrm{Bu}$ sonuçlar "WebQuest Kullanımına İlişkin Öğretmen Algıları" ölçeğinin güvenirlik katsayısının yüksek düzeyde olduğunu göstermektedir. 
Madde ayırt ediciliğini belirlemek amacıyla yapılan t-testi sonuçlarına göre alt \%27 lik puan aralığındakiler ile üst \%27 lik puan aralı̆̆ındakilerin madde puan ortalamaları arasındaki farkın anlamlı olduğu görülmüştür.

WKAÖ'de 41 madde bulunduğu ve 5'li bir derecelemeye sahip olduğu için, ölçekten alınabilecek en yüksek puan 205 , en düşük puan ise $41^{\prime}$ 'dir. Olumsuz soruların tersine çevrilerek puanlanması sonucu ölçekten alınabilecek düşük puanlar kullanıcıların WebQuest kullanımına yönelik olumsuz bir bakış açısına sahip oldukları, yüksek puanlar ise WebQuest kullanımına yönelik olumlu bir bakış açısına sahip olduklarına işaret edecektir. Bu bağlamda ölçek, genel tarama ve durum saptama amaciyla kullanılabilecek bir ölçektir.

WKAÖ'nün geçerlik ve güvenirlik çalışmalarından elde edilen bulgulara göre, ölçeğin kullanıma hazır olduğu ve kullanıcıların WebQuest kullanımına yönelik algılarını belirlemede güvenilir bir şekilde kullanılabileceği söylenebilir. Ölçeğe ilişkin geçerlik ve güvenirlik çalışmaları farklı örneklem gruplarında tekrarlanabilir.

\section{KAYNAKLAR}

Akgül, A. ve Çevik, Ç. (2003). İstatistiksel Analiz Teknikleri. Emek Ofset Bask1, s.104.

Balc1, A. (2005). Sosyal Bilimlerde Arastırma. Ankara: PegemA Yayıncılık

Bartlett, M.S. (1954). A note on the multiplying factors for various chi square approximations. Journal of the Royal Statistical Society, 16 (Series B), 296-298

Brucklacher B. \& Gimbert B. (1999). Role-playing software andWebQuests: what's possible with cooperative learning and computers. Computers in the Schools 15, 37-48.

Büyüköztük, Ş. (2007). Sosyal Bilimler İçin Veri Analizi El Kitabı. Ankara: PegemA Yayınları.

Cruz, S. C.\& Carvalho A. A. (2008). A WebQuest About Tuthankamen. Computers and Education, 21(3), 207-217.

Dodge, B. (1995). The WebQuest Page at San Diego State University [Internet web site]. Retrieved March 23, 2002, from the World Wide Web:http://webquest.sdsu.edu/

Dodge, B. (2001). Five rules for writing a great WebQuest. Learning ve Leading with Technology, 28(8), 6-10.

Gülbahar, Y.; Kalelioğlu, F. ve Mardan, O. (2008). Öğretim ve Değerlendirme Yöntemi Olarak Web Macerası'nın Kullanışlılık 
Açısından Değerlendirilmesi. Ankara Üniversitesi Eğitim Bilimleri Fakültesi Dergisi, 41,(2), 209-236.

Halat, E. \& Jakubowski, E. (2001). Teaching Geometry Using Webquests. Proceedings of the19th International Conference on Technology and Education, Tallahassee, Florida.

Halat, E. (2005). Webquest' in Öğretim Amaçlı Kullanımı. XIV. Ulusal Eğitim Bilimleri Kongresi, 28-30 Eylül 2005 Denizli.

Halat, E. (2007). Matematik öğretiminde webquest' in kullanımına ilişkin öğretmen adaylarının görüşleri, İlköğretim Online, 6(2), 264-283.

Halat, E. (2008). The Effects of Designing Wbequests on the motivation of pre-service elemantary school teachers. International J. Mathematics Education Science and Technology, 39: 793-802.

Kaiser, H. (1974). An index of factorial simplicity. Psychometrika, 39, 31-36

Kurtuluş, A. ve Kılıç, R. (2009). Webquest Destekli İşbirlikli Öğrenme Yönteminin Matematik Dersindeki Erişiye Etkisi. e-Journal of New World Sciences Academy, 4, (1), 62-70

Lim, S. \& Hernández, P. (2007). The WebQuest: An illustration of instructional technology implementation in MFT training. Contemporary Family Therapy, 29 (3), 163-175.

March, T. (1998) . Homepage. WebQuest for Learning. Retrieved May 12, 2008 from the World Wide Web: http://www.ozline.com/webquests/intro.html

Özdamar, K. (2004). Paket Programlar ile Istatistiksel Veri Analizi. Eskişehir: Kaan Kitabevi.

Pohan C. \& Mathison C. (1998) WebQuests: the potential of Internet-absed instruction for global education. SocialStudies Review 37, 91-93.

Tabachnick, B.G. \& Fidel, L.S. (1996). Using multivariate statistics (3rd edition). New York: Harper Collins. Chapter 13.

Tavşancıl, E. (2002). Tutumların Ölçülmesi ve SPSS ile Veri Analizi. Ankara: Nobel Yayın Dağıtım.

Vidoni K. \& Maddux C. (2002).WebQuests: can they be used to improve critical thinking skills in students? Computers inthe Schools 19, 101117.

Zheng R., Stucky B., McAlack M., Menchana M. \& Stoddart S. (2005). WebQuest learning as perceived by highereducation learners. TechTrend, 49, 41-49. 
